\title{
Humanización
}

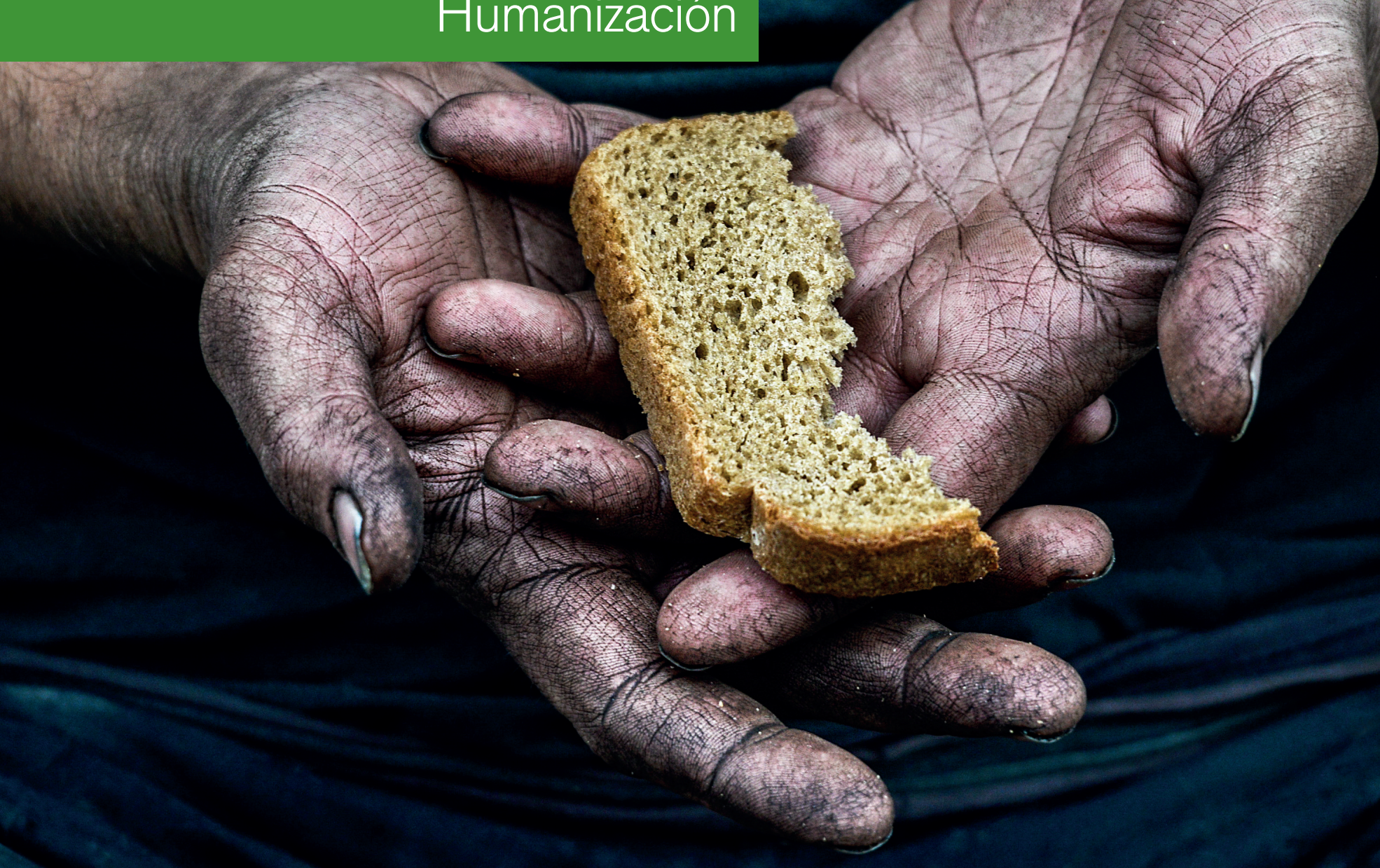

\section{Humanización y acción}

\author{
Humanization and Action
}

(2) Autor

\author{
Jose Carlos Bermejo \\ Centro de Humanización de la Salud, Centro San Camilo \\ E-mail: jcbermejo@humanizar.es \\ Marta Villacieros Durban \\ Centro de Humanización de la Salud, Centro San Camilo \\ E-mail: investigacion@humanizar.es
}


Resumen

Abstract

Key words
En este artículo se revisa el significado de la palabra humanizar y el fundamento de la humanización entendido como vulnerabilidad y dignidad. Se resumen los ámbitos clave para la humanización, como el político-económico, el de la justicia, las estructuras, el cultural y el de la relación interpersonal. Se ahonda en las causas de deshumanización, como son la injusticia, el poder, la incultura y el desarrollo tecnológico, la despersonalización, la burocratización, la corrupción, el dolor y el sufrimiento o la falta de formación. Finalmente se proponen acciones humanizadoras que incluyen los ámbitos revisados.

This paper reviews the meaning of the word humanize and the basis of humanization understood as vulnerability and dignity. The key areas for humanization are summarized, such as the political-economic sphere, justice, structures, culture and the inter-personal relationship. The causes of humanization, such as injustice, power, ignorance and technological development, de-personalization, bureaucratization, corruption, pain and suffering and lack of training are looked into in depth. Finally, humanizing actions that include the reviewed areas are proposed.

Humanización; bioética; ámbitos de humanización; causas de deshumanización.

Humanization; bioethics; areas of humanization; causes of humanization.

Recibido: 19/07/2018. Aceptado: 07/09/2018 


\section{La palabra humanizar. El concepto}

Según la Real Academia Española la palabra humanizar recoge dos significados: el transitivo del verbo "hacer humano, familiar y afable a alguien o algo" y el pronominal del verbo "ablandarse, desenojarse, hacerse benigno". Parece

Humanizar-se pasa por

tomar-se más en cuenta, por

hacer-se más consciente de

la propia realidad, por llegar a

ser más a uno mismo, como

humano que es entonces que, lo de humanizar, se puede hacer en muchas direcciones, hacia los demás, hacia las cosas y hacia uno mismo.

¿Cómo podemos hacernos humanos si ya lo somos? Humanizar-se pasa por tomar-se más en cuenta, por hacer-se más consciente de la propia realidad, por llegar a ser más a uno mismo, como humano que es.

Por otro lado, la humanización se puede aplicar a muchos ámbitos o profesiones, como el mundo de la salud, donde humanizar es algo más profundo y complejo que un conjunto de intervenciones que se reduzcan a la aplicación de técnicas o servicios de ayuda. 0 como el mundo de la ética, donde encontramos decisiones y conflictos ante los que nos encontramos indefensos, incompetentes, con miedo y sin recursos.

Humanizar pasa por incidir tanto en el diseño y desarrollo de programas que cubran las distintas necesidades materiales, como por incidir en la autonomía de las personas y el respeto de los valores, ideas y creencias de cada una de ellas.

En el fondo, humanizar constituye el compromiso ético de considerar a la persona en su globalidad. Y una intervención holística, global, integral, necesita de una particular capacitación de los agentes sociales en el ámbito de la inteligencia del corazón, de las habilidades para entrar en el mundo personal y particular de la persona a la que se quiere acompañar, identificar y movilizar en ella no solo los problemas y necesidades, sino el mundo de los significados, los recursos, las habilidades y los valores que pueden permitirle trabajarse a sí mismo y ser el mayor protagonista del proceso.

Promover la dignidad intrínseca de todo ser humano constituye el fundamento último de toda acción humanizadora. Esta dignidad es la base sobre la que se sustenta toda acción que quiera ver en el otro un semejante y acompañarle a ser él mismo, contribuyendo con su personalidad y su particularidad en la construcción de un mundo más igualitario, más justo, más pacífico, más gozoso y saludable.

\section{El fundamento de la humanización}

Uno de los factores que nos empobrece como seres humanos es la tendencia a ignorar o negar la propia vulnerabilidad. Cuando negamos nuestro dolor, nuestra herida o nuestra vulnerabilidad, estamos negando una gran parte de nosotros mismos $y$, sin darnos cuenta, nos estamos incapacitando. ¿Qué profesional de qué ámbito se autolimitaría no reconociendo la principal herramienta de su actividad? Pues quien aspire a ser profesional de lo humano no puede no reconocer su humanidad. 
Nos cuesta darnos cuenta de que uno de los recursos para humanizar es, indiscutiblemente, considerarse humano. Reconocer, aceptar e integrar no solo alegrías, disfrutes y emociones placenteras sino también dificultades, conflictos, arideces y emociones displacenteras.

Ser humano, nadie lo cuestiona, incluye tener virtudes y defectos. Si evitamos ver nuestros defectos porque nos causan dolor o porque no dan buena imagen, si no somos capaces de integrar su existencia en nuestra cartera de singularidades buscando ser invulnerables, nos convertiremos ciegos. Ciegos a aquello sobre lo que echamos sombra, ciegos a todo el campo de visión que oscurecemos para no ver lo que no nos gusta. Lo oscurecemos y nos convertimos en personas con dobleces, personas escondidas detrás de un escaparate, de una máscara, de una imagen.

El que se sabe vulnerable y

defectuoso, el que se reconoce

en su lado oscuro, no tiene que

esconder nada, como no tiene

nada de lo que defenderse
El que no acepta su lado oscuro, paradójicamente, se oscurece. Se convierte en alguien que trata de evitar riesgos de ser descubierto, alguien que tiene miedo del encuentro -y del desencuentro- con el otro, alguien que siente amenazas y tiene mucho de lo que defenderse. Alguien que no quiere escuchar lo que el otro pueda cuestionarle. Alguien que se sube a una fortaleza y, desde ahí, desde esa atalaya, como en los cuentos infantiles, quiere considerarse invulnerable. Sin comprender - estando tan "asegurado"-por qué se siente tan vulnerable, sin saber cuáles son las amenazas ni de qué se defiende.

Sin embargo, el que se sabe vulnerable y defectuoso, el que se reconoce en su lado oscuro, no tiene que esconder nada, como no tiene nada de lo que defenderse. No tiene miedo de las amenazas, de hecho no considera que existan amenazas, ya que sabe que puede aceptar lo que la vida le traiga. Conoce los riesgos y no se pelea con ellos y si no los conoce, no tiene miedo a encontrarse con ellos. Al final, es el que se sabe vulnerable, el que se siente invulnerable.

Por eso no evita el encuentro con el otro, ni la crítica, ni el desencuentro. El que se sabe defectuoso y conoce su dolor, camina a pie de calle, comprende y se acerca. Se acerca tanto que se pone a la altura del más bajito y, el más bajito, entonces se siente igual. Dignifica.

Dignidad según la RAE significa "excelencia, realce". Solo te puede realzar el que se pone a tu altura. El que se pone en lo alto te abaja. Entre las numerosas actitudes humanizadoras, hemos de reconocer pues, la importancia de la humildad.

Más allá de las diferentes acepciones que el diccionario de la Real Academia presenta hoy, el término "dignidad" designa en latín "lo que es estimado o considerado por sí mismo". Cuando se aplica la palabra dignidad a la persona humana, se le está considerando como un fin en sí misma, como primer criterio de contrastación para la valoración ética de los fines perseguidos. Una de las expresiones más célebres, en este sentido, aparece en una de las formulaciones del imperativo categórico kantiano: "Actúa de tal modo que trates a la humanidad, tanto en tu persona como en la persona del otro, no como un mero medio, sino siempre y al mismo tiempo como fin".

La dignidad humana, como comparten numerosos autores, significa el valor interno e insustituible que le corresponde al hombre en razón de su ser, no por ciertos rendimien- 
tos que sea capaz de prestar, sino por ser un fin en sí misma'. La dignidad, que como tal es un atributo de la persona, "posee una dimensión social, colectiva, en el sentido de que va acompañada de la necesidad de que las demás personas y la comunidad en que el individuo se integra respeten su libertad y sus derechos" ${ }^{\prime 2}$.

La palabra "dignidad" admite, al menos, dos acepciones: "como forma de comportarse (portarse digna o indignamente), o como superioridad e importancia de un ser independientemente de su comportamiento"s. Son, ciertamente, acepciones complementarias, porque una persona se comportará dignamente cuando su conducta se adecue a su condición superior y a la del destinatario de su relación. De lo contrario, el trato será inhumano.

\section{Algunas realidades sobre humanización}

Humanizar es una cuestión ética y transversal. Como iniciábamos, tiene que ver con los valores, con la búsqueda del bien de la persona que se encuentra y del sí mismo, en la relación. Humanizar una realidad consiste en impregnarla de los valores genuinamente humanos, que van más allá del valor

No se trata de humanizar a los

otros, sino que yo he de ser y

vivir humanamente para poder

transmitir humanidad del uso de las técnicas para luchar contra las adversidades de la vida, o mejor, que refieren el fondo del uso de esta, los motivos y los modos que llevan a utilizarlas bien.

Un proceso serio de humanización ha de considerar la necesidad de intervenir desde un lugar concreto y de una forma concreta. No se trata de humanizar a los otros, sino que yo he de ser y vivir humanamente para poder transmitir humanidad. Es decir, todos los seres humanos, tenemos que tomar conciencia, intervengamos o no en algún eslabón de la cadena, de lo que significa ser humano.

Todos los ámbitos pues, son importantes, pero dos son clave: el político-económico y el de la justicia del sistema. El político-económico porque de ello dependerán los objetivos y las pautas a seguir, donde se enmarcan en última instancia los modos de proteger a las personas. El de la justicia, para buscar la igualdad en el reconocimiento de los derechos lo que a su vez tiene un peso muy importante sobre la distribución válida y eficaz de los recursos.

Por eso también la humanización tendrá que contemplar el ámbito, su accesibilidad y la acomodación de las estructuras a las verdaderas necesidades de los destinatarios y de los profesionales. Todos estos aspectos pueden hacer sentir a una persona digna o indigna. Por ejemplo, no es lo mismo poder entrar por uno mismo que tener que pedir

1 Ferrer, U. (1996). La dignidad y el sentido de la vida. Cuadernos de bioética, 16(2), 191.

2 Alegre Martínez, M. A. (1996). La dignidad de la persona como fundamento del ordenamiento constitucional español. León: Universidad de León, p. 19.

3 Millán Puelles, A. (1973). Persona humana y justicia social. Madrid, p. 15. 
ayuda, entrar en un centro con luz, limpio y recogido, con pasillos amplios y buen olor, que entrar en un centro sucio, cerrado y desordenado. Uno se siente diferente, maltratado, despreciado por el sistema que no se ocupa de su bienestar ni del bienestar del familiar.

Respecto al ámbito cultural consideramos importante fomentar el respeto, la educación y las formas de entender la vida y la muerte. Una cultura más humana es aquella que respeta la vida, que promueve estilos de vida sanos, que se interesa por la educación en valores. Una cultura es más humana también cuando no niega la muerte y el dolor como partes necesarias de la vida. Se trata de crear cultura

Una cultura es más humana

también cuando no niega la

muerte y el dolor como partes

necesarias de la vida

en las poblaciones, en las instituciones, en la calle. La cultura que respira una población acaba impregnando el aire con su ánimo. Este ánimo retroalimenta la forma de estar y se va creando tradición y con el tiempo, historia.

Humanizar tiene que ver, pues, con un proceso del individuo y de la colectividad, de hacer digno de la condición humana cuanto se vive. Y esto se realiza por la relación interpersonal. En ella o con ella todo puede tender hacia la personalización y hacia la dignificación o hacia la despersonalización y deshumanización. En ella se respira y se genera cultura.

Humanizar tiene que ver con extraer lo más genuino y natural que tiene el ser humano, con realización del ser humano, o con tomar conciencia de sí mismo para poder ser para los demás, tenemos que encontrar formas de trabajo en las que se pueda cristalizar la humanización de los diferentes ámbitos.

Humanizar tiene que ver con ser algo parecido a una gran familia, con el derecho a que la persona participe en su comunidad, con afectividad y cercanía, el disfrute de las interacciones sociales favoreciendo una vida personal gratificante y libremente elegida. Hay que favorecer el desarrollo del grupo humano, el sistema relacional y los aspectos psicosociales, sin olvidar la multidimensionalidad de la persona.

Humanizar tiene que ver con la ecología y el medioambiente, debemos considerar el mundo nuestro hogar; tenemos que cuidar los recursos naturales y respetar los espacios exteriores e interiores, cuidar la gran casa de todos y dar calidez en la propia.

Humanizar tiene que ver con la integración en la comunidad y por tanto con globalidad. Las personas deben tener posibilidad de desarrollarse en su entorno y tener acceso y posibilidad de disfrutar de los bienes sociales y culturales, en igualdad con el resto de la población.

\section{Causas de deshumanización}

No resulta fácil el análisis de las causas sin caer en un discurso limitante, reductivo, puesto que, como hemos visto, el fenómeno es muy complejo y con muchos aspectos relacionados. Un breve análisis de algunas de las causas de deshumanización tiene que recoger, forzosamente, las siguientes: 


\subsection{La causa fundamental: la injusticia}

En el fondo del proceso de deshumanización hay elementos profundos, que tienen sus raíces más hondas en la misma antropología, en la política, en la economía y en la mala distribución de los recursos del planeta.

La complejidad del mundo actual nos permite hacernos cargo también de que este es reflejo de la cultura general. Existen numerosas injusticias debidas a la economía de mercado imperante en el mundo, que no permiten hablar de acceso igualitario a los recursos. Así mientras que en los países ricos discutimos sobre la proporción u oportunidad de un tratamiento sofisticado (o de su retirada), en numerosos puntos de nuestro planeta la situación es sencillamente escandalosa.

En general, los sistemas

autoritarios de poder contienen

procesos de deshumanización

de las personas a ser

dominadas

En la mayor parte del mundo se muere de enfermedades evitables, curables, pero sin contar con recursos para ello. Entre pobreza y enfermedad hay un estrecho vínculo escandaloso que hace que muchas de las enfermedades sean una manifestación de la pobreza ${ }^{4}$.

Mientras la dimensión ética no entre explícitamente en los planteamientos socioeconómicos en sentido universal, tendremos que hablar de deshumanización. "Cuando los economistas pretenden ser éticamente neutrales caen en la enfermedad del positivismo y del formalismo. Por otra parte, todo conocimiento científico está impregnado de valores y la neutralidad ética no es posible porque la indiferencia, en sí misma, ya es una posición moral"5.

\subsection{Los sistemas autoritarios de poder}

Los procesos de deshumanización están íntimamente relacionados con los sistemas de dominación y poder. En general, los sistemas autoritarios de poder contienen procesos de deshumanización de las personas a ser dominadas. En ellos se da una cultura impersonal de las instituciones prestadoras de servicios, así como con la relegación de la importancia del contacto a favor de los avances tecnológicos.

Detrás de muchos aspectos cotidianos de la deshumanización a gran y pequeña escala están personas que hace un uso del poder en beneficio propio. Un poder sin corazón, un poder que desencadena legislaciones capaces de mercantilizar la protección social y someter a los ciudadanos a los dinamismos del mercado y del beneficio.

Se produce una hipertrofia del "poder" anteponiendo las exigencias de la política del momento a cualquier necesidad de la persona. Esto lleva consigo la "cosificación" del

4 Bermejo, J. C. (Ed.) (2008). Salud y justicia. Madrid: PPC.

5 García, A. (1990). Presupuestos de una economía humanizante. Corintios XIII, (53), 145. 
ciudadano, instaurando una relación objetal parcial y considerándolo un número más en la lista de solicitudes ${ }^{6}$.

\subsection{La deshumanización de la salud: incultura y desarrollo tecnológico}

En la praxis comprobamos -como dice Rocamora7- que junto a beneficios notables (prolongación de la vida, disminución del dolor, etc.) se arrastran graves inconvenientes. Entre otros, hacer del enfermo una máquina corporal averiada y del profesional de la salud un mecánico, y aumentar de forma progresiva la separación entre ambos. En esta situación podemos hablar de cultura reduccionista y la tecnólatra.

\section{Existe una amplia corriente}

de pensamiento que asocia el

desarrollo de la tecnología con

la deshumanización
El primero llevaría a minimizar de tal forma el enfermar humano, contemplándolo solo con el prisma de la técnica y buscando el remedio solo a través de la ciencia instrumental. El segundo llevaría a depositar toda nuestra capacidad de curación solo en los procedimientos técnicos, olvidando que también la palabra y el encuentro son medios eficaces de sanación y de cuidados.

La universalización de los servicios de salud y su tecnificación hacen también que estos terminen organizándose como una empresa. Una empresa compleja, una red de redes que no solo afecta al hospital, sino a todo un mundo de organización. En efecto, la tecnología se puede volver tirana ${ }^{8}$, es decir, puede hacer que se filtre la idea de que cada descubrimiento científico y tecnológico constituye un progreso y, como tal, debe ser necesariamente empleado. "Esta tiranía se sostiene y perpetúa por un juego de fuerzas que comprende la solicitud del cliente, el deseo de los profesionales de ofrecer productos (curación/cuidados) y la búsqueda de beneficio por parte del hombre de negocios"s.

Por ello, existe una amplia corriente de pensamiento que asocia el desarrollo de la tecnología con la deshumanización. Desde este enfoque en general se sostiene que la tecnología tiene el efecto de entorpecer las relaciones humanas aislando y alienando a las personas.

Una afirmación frecuente es que junto al desarrollo de la técnica ha ido produciéndose y creciendo un proceso de deshumanización. A veces el discurso cobra incluso tonos nostálgicos, halagando aquella medicina pobre en medios (conocimientos, métodos diagnósticos y terapéuticos), que hacía abundante uso sobre todo de uno de los recursos existentes: la relación humana al servicio del enfermo.

6 Rocamora, A., O.C., 97-98.

7 Rocamora, A. (2000). Un enfermo en la familia. Claves para la intervención psicológica. Madrid: San Pablo, p. 19.

8 Cf. Geiger, H. J. (1975). The causes of deshumanization in helth care and prespects for humanization. En J. Hovard \& A. Strauss (Eds.), Humanizing helth care (p. 27). Nueva York.

9 Brusco, A. (1983). Umanità per gli ospedali. Varese: Salcom, p. 27. 
Con frecuencia, nos parece asistir a un discurso reductivo que lleva, también, a constatar el peligro de contraponer técnica y humanización. Quizás esta oposición tenga raíces ancestrales. Símbolo de ella puede ser el mito de Prometeo, según el cual, este robó al dios Zeus la semilla del fuego, símbolo de las habilidades técnicas y de la capacidad de transformar la naturaleza y, por desmesurado e imprudente, Zeus le castigó atándole a una columna y enviándole un águila voraz que le devoraba el hígado que se iba regenerando en un suplicio eterno.

\section{Parecería como si el \\ humanismo se sintiera \\ acomplejado y el técnico \\ omnipotente, con lo que uno y \\ otro se obnubilan sin remedio}

Prometeo representa, por un lado, al bienhechor de la humanidad porque entrega al hombre la capacidad de transformar con la técnica la naturaleza y, por otro, la desmesura y la imprudencia porque si no es utilizada bien, la técnica acarrea necesariamente desgracias en forma de pobreza para muchos y riqueza para pocos, guerras, desavenencias sociales, envidias, etc. Así, la técnica aparece en el imaginario cultural con frecuencia dotada de poderes demoníacos, contranaturales, antihumanos, como si hubiera un persistente enfrentamiento entre humanidades $y$ técnica.

Parecería como si el humanismo se sintiera acomplejado y el técnico omnipotente, con lo que uno y otro se obnubilan sin remedio.

Miguel Delibes, rechazando una torpe idea del progreso, escribe: "Mis personajes son conscientes, como lo soy yo, su creador, de que la máquina, por un error de medida, ha venido a calentar el estómago del hombre pero ha enfriado su corazón"10. Ciertamente no es la máquina quien enfría el corazón, sino su creador y el que la usa. Porque también la máquina da calor al corazón si quien la usa lo hace bien y para objetivos dignos.

Sin duda, el proceso de inmersión en la tecnificación creciente, la colonización tecnológica de los procesos de sanación plantea grandes interrogantes que han de formar parte de la reflexión bioética.

\subsection{La despersonalización}

Ortega y Gasset decía que la técnica es incapaz de determinar el contenido de la vida. Si cuidar a un ser humano tiene que ver con la acción de ayudarle a ser él mismo -afirma Torralba-, esta tarea solo puede desarrollarla un sujeto, esto es, alguien que está llamado, también, a ser él mismo. Cuidar es una tarea ineludiblemente humana y lo es porque a través de ella se pone en juego la cuestión del sentido de la existencia, la cuestión de la libertad, la cuestión de la intimidad y de la autenticidad. Este tipo de categorías forma parte del universo personal y solo una persona, debidamente cultivada, puede ayudar a otra a encauzar correctamente dichas categorías en su vida personal ${ }^{11}$.

10 Delibes, M. (1994). Un mundo que agoniza. Barcelona: Plaza \& Janés, p. 41.

11 Torralba, F. (1993). Lo ineludiblemente humano. Hacia una fundamentación de la ética del cuidar. Labor Hospitalaria, (253), 178. 
Tillard, quizás en tono pesimista, ha descrito la situación así: "La inmoralidad de un mundo sin afecto se imprime también en el ejercicio de las profesiones sanitarias". El timbre se convierte en el único medio para recurrir a una presencia, que con frecuencia será la de una enfermera al límite de la resistencia. "La inmoralidad de nuestro mundo ofende al hombre y lo afecta justamente en su lucha contra la enfermedad, el sufrimiento y la muerte. Es el colmo del absurdo"12.

Algún autor, como Omar Sultan Haque y Adam Waytz, de la Universidad de Harvard, a la vez que denuncia el proceso de deshumanización y reclama la necesaria actitud empática como potencial clave de humanización, dice que es necesario distinguir cuando la deshumanización es útil cuando no lo es. Argumenta que la deshumanización es útil solo en contextos específicos tales como cuidados intensivos. Waytz dice que "la funcionalidad de la deshumanización varía violentamente a través de las especialidades desde pediatría a cirugía ortopédica". A la vez, insisten en la necesidad de eliminar lo que llaman la "ceremonia de la bata blanca"13. Aun siendo un modo provocador de decirlo, evocan esa parte de intervenciones en salud que comportan una alta dosis de necesaria mirada objetivadora (solo puntual y transitoria) al cuerpo humano para proceder a prácticas terapéuticas. Es aquí donde indebidamente, a mi juicio, se excusan algunos profesionales argumentando la necesaria distancia y frialdad y extrapolando la actitud debida de algunas intervenciones al ser profesional en general.

\subsection{La burocratización}

En ocasiones, la solicitud y la

compasión son reemplazadas

por reglas frías e impersonales

del contrato de trabajo
En efecto, la burocratización exagerada que padecemos conlleva una despersonalización lamentable. Y podemos afirmar con Marchesi que, de esta manera, la persona se convierte en objeto de experimentación atendida en cadena, como en un montaje de automóviles. La deshumanización en los servicios aumenta el malestar $y$, con frecuencia, es causa y origen de nuevos conflictos ${ }^{14}$.

La responsabilidad individual, el mundo de los valores quedan interpelados por este proceso de deshumanización. A veces el trabajo es visto exclusivamente en términos remunerativos. En ocasiones, la solicitud y la compasión son reemplazadas por reglas frías e impersonales del contrato de trabajo. Expresiones como: "no es mi responsabilidad", "no me pagan por esto", "mi turno ha terminado, espere al próximo" etc., pueden indicar el afianzamiento de una mentalidad centrada en los propios derechos e intereses -legítimos-, dejando al demandante en una situación de desamparo.

Esto ha favorecido la aparición de otro elemento deshumanizador: el incremento de relaciones funcionales, más que personales. Al haberse universalizado los servicios, puede llevar consigo también el hecho de que la sociedad haya generalizado modos de

12 Tillard, J. M. R. (1980). Mondo sanitario, terra di vangelo. Testimoni, (14), 35.

13 La deshumanización de la medicina moderna, disponible en: http://ecodiario.eleconomista.es/interstitial/volver/acierto-julio/salud/ noticias/3833541/03/12/La-deshumanizacion-de-la-medicina-moderna.html, consultado en julio de 2013.

14 Marchesi, P. L. (1993). Humanicemos el hospital. En AA. VV., Humanización en salud (p. 58). Bogotá: Selare. 
intervención que en el pasado reservaba únicamente a los pobres, a los más débiles, a los más resignados e incapaces de denunciar actitudes deshumanizadoras en relación a ellos ${ }^{15}$.

La excesiva burocratización de los sistemas provoca que el personal utilice mucho de su tiempo en actividades procedimentales, burocráticas. Resulta evidente que la burocratización es algo inevitable cuando se trata de coordinar y atender a una masa humana (...); sin embargo en el plano ético, la burocratización altera negativamente el sentido y la esencia de los procesos (... $)^{16}$.

\section{Resulta evidente que la \\ burocratización es algo \\ inevitable cuando se trata de \\ coordinar y atender a una masa \\ humana; sin embargo, en el \\ plano ético, la burocratización \\ altera negativamente el sentido \\ y la esencia de los procesos}

Según Weber, la burocracia puede degenerar de las siguientes maneras: la jerarquía vertical de autoridad puede no ser lo suficientemente explícita o delineada, causando confusión y conflictos de competencia; las competencias pueden ser poco claras y usadas contrariamente al espíritu de las reglas; en ocasiones el procedimiento en sí mismo puede considerarse más importante que la decisión o, en general, sus efectos; nepotismo, corrupción, enfrentamientos políticos y otras degeneraciones pueden contrarrestar la regla de impersonalidad, pudiéndose crear un sistema de contratación y promoción no basado en méritos; los funcionarios pueden eludir responsabilidades; la distribución de funciones puede ser inefectiva, produciendo excesiva actividad regulatoria, duplicación de esfuerzos y, en general, ineficiencia ${ }^{17}$.

\subsection{La corrupción}

La corrupción es tan compleja e involucra tantos actores, que no existe una fuente de corrupción más importante que otra, y como afirma la alemana Karen Hussmann experta en anticorrupción y gobernabilidad, es tanto causa como consecuencia de los gobiernos; por esto, los problemas comprenden desde el chequeo y el balance, la falta de información clara que permita identificar dónde funcionan mal las cosas, los problemas en el control, problemas en la integridad y capacidad de las instituciones, y en los incentivos, por lo que las personas aprovechan para sacar dinero. Estas expresiones se dan a nivel nacional, regional, institucional..., donde existen actores que están permeando el sector para sus propios fines.

La corrupción alcanza, en ocasiones, envergaduras inimaginables y constituye porcentajes de desviación de recursos económicos a intereses privados sin límite. En otras ocasiones, el mal uso de los bienes es a pequeña escala (profesionales que hacen uso

15 Cf. Sandre, G. de (1986). A servizio di chi sono i servizi sociali e saniatari? En AA.VV., Il rispetto delle persone nei servizi sociali e sanitari (p. 14). Padua: Fondazione Emanuela Zan.

16 Torralba, F. (1999). Lo ineludiblemente humano: hacia una fundamentación ética del cuidar. Labor Hospitalaria (253), 180.

17 Ver: http://es.wikipedia.org/wiki/Burocracia consultado en julio 2013. 
personal, familiar, de recursos públicos), pero que contribuyen, en todo caso, a degradar el clima ético y a encarecer los costos de los servicios.

La corrupción junto con la pobreza, la desigualdad, los conflictos civiles, la discriminación y la violencia es un tema primordial que no se ha tratado lo suficiente dentro del marco de estos derechos básicos. Lleva a la distorsión de las prioridades en los gastos, lo que redunda en el descuido de algunas comunidades o perfiles sociales.

Es indispensable que los reguladores, los profesionales y los administradores de los sistemas aseguren la introducción y promoción de códigos de conducta, a través de una capacitación continua en todo el sistema orientada a la transparencia. Estos códigos deben constituir una referencia explícita para prevenir la corrupción y los conflictos de intereses que pueden traducirse en ciertos actos, incluso delictivos, y presentar sanciones detalladas para las infracciones, que deben ser implementadas por un organismo independiente.

\subsection{El dolor y el sufrimiento}

Una de las causas de deshumanización es la presencia de dolor evitable en el mundo. La mayor parte del mundo no cuenta con la facilidad que unos cuantos países tenemos de acceder sin límite a medidas de control del dolor, de tal modo que podemos afirmar que, de la mano de la injusticia, asistimos a un escenario de dolor evitable en una cultura paradójicamente indolora.

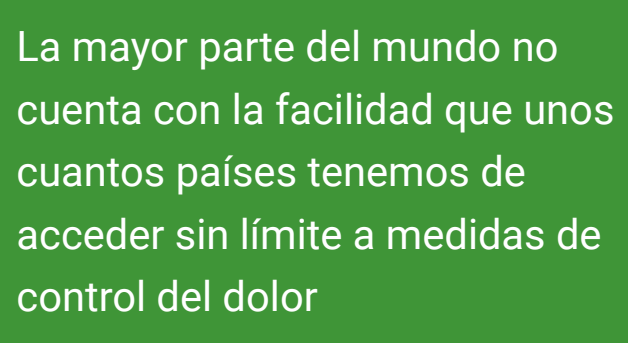

Una cara de la cultura indolora es la lucha a muerte contra la muerte. La no integración de la muerte conlleva, en muchas ocasiones, dejarse llevar por un gran número de falsas esperanzas: otro centro más avanzado, un fármaco experimental, un aparato más sofisticado van a lograr vencer la muerte. Se depositan esperanzas desmedidas en la medicina, como si fuera la ciencia de alargar la vida, provocando así una profunda deshumanización del morir $^{18}$.

A principios del siglo XXI, Eric J. Cassell, un profesor de la Facultad de Medicina de la Universidad de Cornell, publicó en The New England Journal of Medicine, un artículo que luego se convertiría en libro con el mismo título: "La naturaleza del sufrimiento y los objetivos de la medicina". Pocos años más tarde un nuevo artículo de Callahan, con el título "La muerte y el imperativo investigador" vuelve sobre el mismo tema y concluye que "los objetivos de la medicina son dos, y ambos de la misma categoría y la misma importancia; por una parte, permanece el objetivo médico de los últimos siglos, luchar contra las enfermedades; pero, por otra, cuando, a pesar de todos nuestros esfuerzos, 
llegue la muerte -ya que nuestra especie nunca podrá posponerla indefinidamenteconseguir que los pacientes mueran en paz ${ }^{19}$.

\subsection{La falta de formación}

La formación centrada de forma casi exclusiva en el desarrollo de habilidades técnicas, en detrimento de los contenidos filosóficos y antropológicos humanistas, casi inexistentes en los programas de pre y posgrado de cualquier profesión, unido a la enseñanza de una ética limitada a códigos administrativos y procedimentales o a la presentación de leyes o códigos deontológicos, genera como resultado profesionales (en el mejor de los casos) con un nivel de saber elevado, con gran pericia técnica, pero con una paupérrima formación humana y la consecuente incapacidad para interactuar con competencias relacionales, emocionales, éticas

Las competencias blandas

son aquellos atributos o

características de una persona

que le permiten interactuar

con otras personas de manera

efectiva y espirituales con los usuarios o clientes del sistema. Estamos lejos de una perspectiva holística e integradora.

Además, a pesar de los progresos realizados con cierto boom al que hemos asistido en organización de acciones formativas sobre bioética, aún son muy escasos los espacios de análisis y reflexión sobre la bioética médica e incluso inexistentes los relacionados con una ética de la equidad y de la buena gestión de los recursos. Más fácilmente se ha focalizado el debate suscitado por las nuevas tecnologías, dejando de lado los viejos temas éticos de la praxis y la ética de la cotidianeidad, de alta intensidad y de menor complejidad en el razonamiento filosófico que otros temas que dan más espacio a titulares de medios de comunicación.

La ausencia de competencias blandas es causa de deshumanización por el perfil profesional que adquiere la persona que no las desarrolla. Las competencias blandas son aquellos atributos o características de una persona que le permiten interactuar con otras personas de manera efectiva. No son solo un ingrediente en particular, sino que son el resultado de una combinación de habilidades sociales, de comunicación, de forma de ser, de acercamiento a los demás y otros factores que hacen a una persona dada a relacionarse y comunicarse de manera efectiva con otros. Son especialmente necesarias para las profesiones de ayuda en la vulnerabilidad.

Las competencias blandas (como elemento a relacionar con las "duras", es decir, las científico-técnicas), tienen relación con lo que se conoce como inteligencia emocional, inteligencia moral, inteligencia espiritual, inteligencia cultural... La relación y comunicación efectiva se ve afectada principalmente por la capacidad de conocer y manejar las emociones, los valores, tanto en nosotros mismos como en los demás. También se puede utilizar el término de "competencias interpersonales" para agrupar a estas habilidades en una persona. 
Formados especialmente para la competencia técnica y la eficiencia, los profesionales se encuentran, con frecuencia, sin recursos para manejar las dificultades interpersonales y personales. Trabajar en equipo requiere no solo competencia técnica y buena disposición, sino formación específica para ello, particularmente para manejar los conflictos y para escucharse. Allí donde no se produce la escucha es difícil que alguien no padezca los efectos catastróficos que su ausencia produce.

A modo de resumen, en último término, en el fondo de la deshumanización está el olvido de la propia condición de personas, como seres morales que se realizan como tales cuando buscan el bien ajeno y propio, cuando salen al paso de la fragilidad con la fortaleza, ambas constitutivas de su ser, cuando se reconocen sanadores heridos, empujados a la búsqueda del bien en la relación intersubjetiva y solidaria. Tenemos una indigencia fundamental que nos hace mendigos unos de otros, como dice Boff; y

No teniendo como objetivo

la salud, el sistema sanitario carece de cultura de salud y no está en condiciones ni de asumir su propia salud, ni de controlar el sistema sanitario somos portadores, a la vez, de una riqueza inagotable que nos hace donantes unos de otros; tenemos, en el fondo algo que dar $y$ algo que recibir.

Más aún, como introducíamos, en el proceso de deshumanización influyen mecanismos psicológicos de negación de la dimensión negativa y oscura de la vida. Con frecuencia se alude a la deshumanización de las grandes instituciones hospitalarias, a la dificultad del personal sanitario para acompañar humanamente al enfermo al final de la vida o en fases avanzadas y crónicas, se suele criticar la falta de información al enfermo y las mentiras que se crean a su alrededor, pero más raramente se reconoce que detrás del acompañamiento a toda persona enferma (en la que de alguna manera la muerte se da cita bajo forma de alguna pérdida o conjunto de pérdidas), nuestra cultura tiende a tabuizar.

Quizás otro elemento que esté en el fondo de la deshumanización sea el hecho de que la ideología médica manifiesta más interés y está más centrada en la enfermedad que en la salud. No teniendo como objetivo la salud, el sistema sanitario carece de cultura de salud y no está en condiciones ni de asumir su propia salud, ni de controlar el sistema sanitario. En el fondo, es el proceso de medicalización de la medicina al que se ha referido Ivan Illich y que hace que todos los aspectos de la vida humana se conviertan en problemas de competencia de los especialistas médicos y que lleva a que el número de enfermos se multiplique velozmente en la sociedad. Al transformar a los enfermos en consumidores pasivos, en objetos que hay que reparar, en meros espectadores de su realidad, la empresa médica socava el deseo de la gente de vivir su realidad. Reduce nuestra capacidad individual a ocuparnos de nuestro cuerpo y a curarnos a nosotros mismos ${ }^{20}$. 


\section{La acción humanizadora}

No queremos terminar este trabajo de reflexión dejando un poso de desesperanza en el lector, puesto que hay mucho que hacer $y$, de hecho, mucho se está haciendo ya. Tanto humanizar como dignificar son verbos activos, así que, hablando en positivo, ¿qué iniciativas se pueden implementar para humanizar?

El Centro de Humanización de la Salud, dentro de un solo ámbito, el sociosanitario, abarca y recoge distintas acciones humanizadoras. Podría decirse que la principal es la formación para la humanización, pero seguido muy de cerca actúa sobre la humanización de las infraestructuras, sobre la gestión de la organización, sobre la difusión de la cultura de la humanización y sobre la salud psicoemocional de los profesionales y de los equipos, siendo el objetivo último, el bienestar de las personas a las que atiende y con las que colabora.

Humanizar es una cuestión

que afecta a las diferentes

dimensiones y escenarios en los

que tiene lugar el cuidado
Iniciativas concretas relacionadas con la formación para la humanización recoge tanto la formación de postgrado y másteres para profesionales sociosanitarios (en relación de ayuda y counselling, en cuidados paliativos, en humanización de la salud), como propuestas formativas con la finalidad de cualificar y mejorar la empleabilidad de personas en riesgo de exclusión social (para personas en situación de desempleo, de baja cualificación, colectivos discriminados), formación que pretende construir un itinerario de inserción que favorezca la autonomía personal y facilite la integración sociolaboral.

Como avanzábamos, humanizar es una cuestión que afecta a las diferentes dimensiones y escenarios en los que tiene lugar el cuidado. Por eso, la forma de humanizar las infraestructuras, en la unidad de cuidados paliativos, tiene que ver con favorecer la accesibilidad y funcionalidad de los espacios, pero también con ambientarlos. Buscando espacios acogedores sin perder la practicidad, el arte ha servido de inspiración en la unidad y se ha distribuido en los diferentes sectores en los que queda dividida la unidad: la literatura, la pintura, la música y la escultura.

Centrándonos en los profesionales del centro, es sabido que su exposición en el ámbito de su trabajo, no solo tiene que ver con su nivel técnico, que también existe, sino con su salud psicoemocional, ya que es una persona en relación. Humanizar las relaciones tiene que ver con sanear también este aspecto; las relaciones con el residente-usuario, con los familiares o con los compañeros mismos conllevan unas vivencias psicosociales determinadas y una implicación emotiva, en ocasiones desbordante, que es necesario atender. Para un manejo sano del estrés y para poder regular el grado de implicación en el cuidado, se llevan a cabo los llamados grupos Balint. En ellos, coordinados por un profesional externo al equipo, los profesionales del centro reflexionan sobre la experiencia subjetiva en su tarea cotidiana, con el fin de mejorar cualitativamente la atención a los residentes o usuarios, a sus pacientes, a las familias y las relaciones entre ellos mismos. 
Para crear equipo, identidad y cohesión, para que se respiren los valores, para crear cultura humanizadora se celebran jornadas específicas. En el día M, de memorias, participan todos los empleados y colaboradores; es un día para recoger y compartir, en un ambiente distendido, lo conseguido en el año. En el día $\mathrm{H}$, de humanizar, participan responsables, empleados y colaboradores y su objetivo es tratar temas de convivencia, desarrollo de las personas y novedades previsibles. El día $\mathrm{R}$, de retiro, está dirigido por el responsable de asistencia espiritual y centrado en la reflexión sobre los aspectos espirituales y humanizadores de la asistencia. Participan todos los empleados que lo deseen.

Por último, la presencia del Comité de Ética Asistencial (CEA) (creado en 1996), tiene como objetivo proporcionar una atención adecuada a la dignidad de la persona. El CEA se posiciona como elemento de análisis, reflexión, consulta y apoyo para profesionales, usuarios, familias y voluntarios, sobre aspectos relacionados con la atención geriátrica y el final de la vida, particularmente en los casos de conflicto ético. Lo constituyen un grupo de personas de carácter abierto e interdisciplinar. 